\title{
Economic security management of the transportation process in the formation of competitive advantages of rail transport
}

\author{
Lidia Shkurina ${ }^{1 *}$, Eugenia Maskaeva ${ }^{1}$, and Stanislav Maskaev ${ }^{1}$ \\ ${ }^{1}$ Russian University of Transport, Moscow, Russia
}

\begin{abstract}
The authors reviewed the resource support of the transportation process security from the point of view of a promising direction as competitiveness and increase the sustainability of rail transport, accidents and events, their number and the damage suffered as well as transport analysis from the point of view of economic management security.
\end{abstract}

\section{Introduction}

Modern conditions require the search for new methods of economic management to create conditions for the sustainable operation of rail transport at a time when competition is increasing between two carriers. Describing the overall transport complex of the Russian Federation and its place in socio-economic development, it should be noted that it has a significant share in the value of fixed assets of the country $(18 \%)$, gross domestic product $(6 \%)$, investment in fixed assets $(11 \%$ of the total investment in fixed assets) and in number of employees (6.4\% of the total number of people employed in the economy). Transport has characteristic of a powerful catalyst, as it directly increases the level of production and commercial activity in all areas of business, allowing you to expand the scale of production, to develop new territories and incorporate new resources into circulation, allows you to link production structures and product markets.

In the structure of cargo arriving on transport, commodity goods with low value added prevail, they, with extreme sensitivity to the tariffs for their transportation, create a significant burden on the transport infrastructure. This situation leads to an increase in the transport component in GDP. A modern transport complex as a whole satisfies the demand for the transportation of goods and passengers, which directly depends on the volume of production in cargo-generating industries, the real incomes of the country's population and the scale of foreign economic activity.

Today, the economic situation in the transport complex is mixed. On the one hand, to ensure the required level of quality and flexibility, it is necessary to talk about the effective interaction of different types of transport in a single logistics chain, focused on the highest quality standards of the transportation process. On the other hand, a competitive transport market requires each carrier to focus on the competitiveness of its transportation process

\footnotetext{
${ }^{*}$ Corresponding author: efut2012@gmail.com
} 
and the quality of transport products. The leader in the freight market is rail transport, which have $86 \%$ of the freight turnover of the transport complex (Table 1).

Table 1. Structure of loading and turnover by types of transport.

\begin{tabular}{|c|c|c|c|c|}
\hline \multirow{2}{*}{ Type of transport } & \multicolumn{2}{|c|}{ Freight loading, \% } & \multicolumn{2}{c|}{ Freight turnover, \% } \\
\cline { 2 - 5 } & $\mathbf{2 0 1 0} \mathbf{\Gamma} \cdot$ & $\mathbf{2 0 1 7} \mathbf{\Gamma} \cdot$ & $\mathbf{2 0 1 0} \mathbf{~} \mathbf{.}$ & $\mathbf{2 0 1 7} \mathbf{~} \mathbf{.}$ \\
\hline $\begin{array}{c}\text { Railway transport } \\
\text { (transportation of } \\
\text { goods on public roads) }\end{array}$ & 12,1 & 12,8 & 84,3 & 86,0 \\
\hline Automobile transport & 55,4 & 55,1 & 9,4 & 8,7 \\
\hline Inland water transport & 1,3 & 1,2 & 3,1 & 2,3 \\
\hline Sea transport & 0,2 & 0,2 & 1,7 & 1,6 \\
\hline Air Transport & 0,01 & 0,01 & 0,2 & 0,3 \\
\hline $\begin{array}{c}\text { Railway transport } \\
\text { (transportation of } \\
\text { goods by non-public } \\
\text { roads) }\end{array}$ & 31,0 & 30,7 & 1,3 & 1,1 \\
\hline $\begin{array}{c}\text { Total transport } \\
\text { complex }\end{array}$ & 100 & 100 & 100 & 100 \\
\hline
\end{tabular}

The dynamics of cargo loading and cargo turnover by types of transport is presented in Fig.1. In general, it can be noted that the increase in loading and cargo turnover was observed on all types of transport, except for inland water transport. 
Railway transport

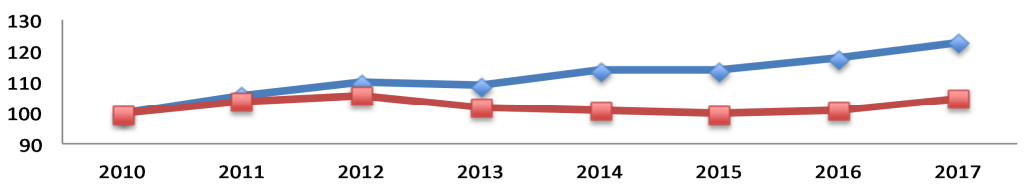

Automobile transport

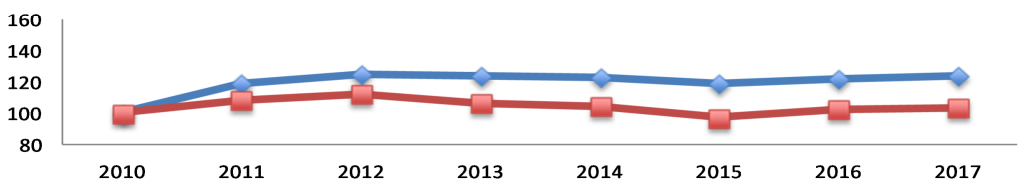

Sea transport

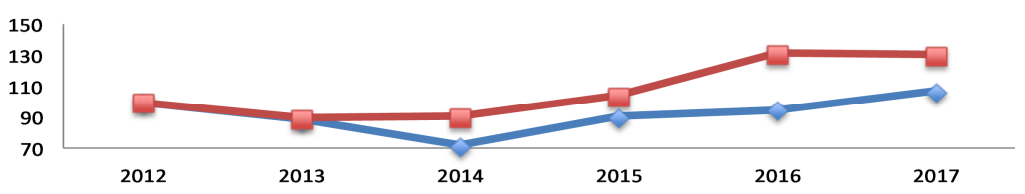

Inland water transport

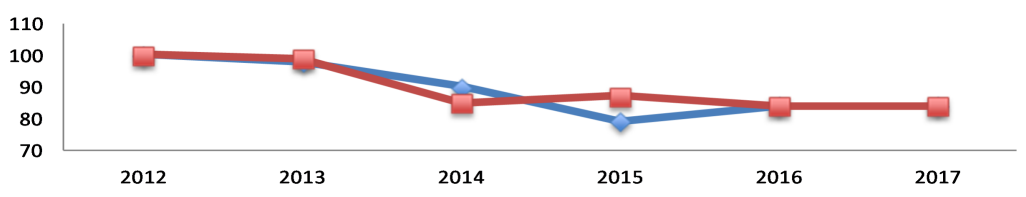

Air transport

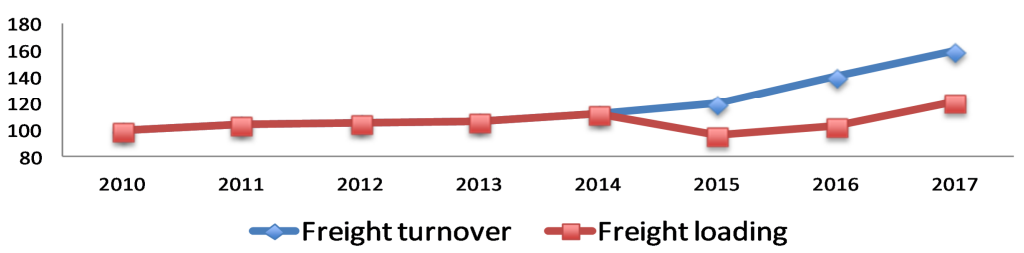

Fig. 1. Dynamics of cargo loading and cargo turnover by types of transport in $\%$ by 2010 .

\section{Materials and Methods}

Competition in the transport market imposes requirements on the quality of transport products, which is a complex of properties and informal characteristics, among which customers distinguish: the tariff for the transportation of goods, the time or speed of delivery, the safety of cargo and the safety of the transportation process.

In railway transport, this most important quality requirement of customers is realized by ensuring transport safety and train traffic safety. In accordance with Resolution No. 495 of the Government of the Russian Federation of April 26, 2017 “On Approving Requirements for Ensuring Transport Security, Including Requirements for the Anti-Terrorism Security of Objects (Territories) Considering Security Levels for Different Categories of Transport Infrastructure Objects and Railway Vehicles" the owner of the infrastructure (JSC Russian Railways) must assess the vulnerability of all objects involved in the implementation of the transportation process. 
At the same time, JSC "Russian Railways" resolves issues of ensuring the safety of train traffic in order to prevent traffic accidents and events related to the violation of traffic safety rules and the operation of railway transport when moving rolling stock, equipment and machinery and causing harm to life or health of individuals, harm to the environment, property of individuals or legal entities [1]

Thus, ensuring transport safety and traffic safety of trains, JSC Russian Railways implements a reliable and economically justified state of guaranteed quality of the transportation process in a single system operating in an inextricably linked technically, technologically and organizationally chain. To assess the level of traffic safety of trains, a natural indicator is defined, calculated by formula:

$$
K=\frac{M}{\sum N S}
$$

where $\mathrm{M}$ - the number of traffic accidents and events for the period;

$\Sigma \mathrm{NS}$ - train-kilometers for the period.

as well as a value indicator characterizing the damage incurred, calculated by the formula:

$$
Y=Y_{1}+Y_{2}+Y_{3}+\cdots+Y_{19}+Y_{20}+Y_{21}
$$

where $Y$ - damage due to traffic accidents and other events;

$Y_{1}$ - damage from accidents with freight cars;

$\mathrm{Y}_{2}$ - damage from accidents with passenger cars;

$\mathrm{Y}_{3}$ - damage from accidents with rolling stock;

$\mathrm{Y}_{4}$ - damage from accidents with train and rail buses;

$\mathrm{Y}_{5}$ - damage from accidents with track machines;

$\mathrm{Y}_{6}$ - damage from accidents with high-speed passenger trains and cars;

$\mathrm{Y}_{7}$ - damage from accidents with track and facilities;

$\mathrm{Y}_{8}$ - damage from accidents with automation and remote control devices;

$\mathrm{Y}_{9}$ - damage from accidents with electrification and power supply devices;

$\mathrm{Y}_{10}$ - damage from accidents with communication devices and structures;

$Y_{11}$ - damage from accidents with other infrastructure;

$Y_{12}$ - costs for the work of a recovery train;

$\mathrm{Y}_{13}$ - damage from defect and loss of cargo;

$\mathrm{Y}_{14}$ - damage from defect and loss of baggage;

$\mathrm{Y}_{15}$ - additional costs associated with delays of trains;

$\mathrm{Y}_{16}$ - component of damage associated with carrier penalties for delays of long-distance passenger trains and local trains;

$\mathrm{Y}_{17}$ - component of damage associated with the carrier's penalties for violation of the terms of delivery of baggage;

$\mathrm{Y}_{18}$ - component of damage associated with carrier penalties due to violation of the terms of cargo delivery to the instructor;

$\mathrm{Y}_{19}$ - damage from harm to life, health and property of third parties involved in a traffic accident or other event;

$\mathrm{Y}_{20}$ - ecological damage;

$\mathrm{Y}_{21}$ - other components of damage.

The dynamics of these indicators in Russian Railways has a positive tendency to decrease in both the number of traffic accidents and the damage suffered as a result of them.

Despite the steady decline in the number of violations of traffic safety, the following objectives have been defined in the Long-Term Development Program of Russian Railways [2]:

- ensuring the safety of life and health of people; 
- ensuring a defined level of traffic safety that meets international and national requirements for the preservation of cargo, rolling stock, infrastructure facilities;

- minimizing the consequences of traffic accidents.

When planning management decisions aimed at improving competitiveness in the transportation market and, accordingly, the quality of transport products, taking into account the fact that the process of transport products manufacturing and its consumption are not separable in time, special attention should be paid to economic management of traffic safety.

\section{Results and Discussion}

The economic management of the safety of the transportation process involves the planning of such engineering and financial support for its organization, which will ensure stable protection of the interests of cargo owners, passengers, owners of rolling stock, owners of infrastructure from all types of real and potential threats of accidents and events. For these purposes, it is reasonable to form the valuation of all necessary resources [2], to ensure the planned level of safety of the transportation process. The calculation can be made according to the formula:

$$
E L S=\sum_{i=1}^{k}\left(\sum_{j=1}^{n} f_{i j}\right) \cdot \overline{P_{i}}
$$

where $E L S$ - the cost equivalent of the required resources to ensure the planned level of traffic safety;

$\bar{P}_{l}$ - colon $(0,0, \ldots \ldots 0,1,0, \ldots .0)$ in i-place- 1 , the rest 0 ;

$f_{1 j}$ - investment resources for the implementation of measures for the "Traffic Safety Program";

$f_{2 j}$ - information resources used to ensure the safety of the transportation process;

$f_{3 j}$ - financial resources for training and raising the skill level of staff engaged in transportation activities;

$f_{4 j}$ - organizational resources to ensure a safe and uninterrupted transportation process;

$f_{5 j}$ - costs associated with the work of recovery trains in the aftermath of traffic accidents and events;

$j$ - specific branch and its structural units engaged in transportation activities;

$i$ - type of a specific resource.

The calculations performed according to this formula can give an impartial assessment of the planned resources to ensure the safety of the transportation process for each structural unit, branch and an aggregate assessment for the company as a whole.

\section{Conclusions}

The ongoing assessment of resourcing of transportation process security and the analysis of traffic incidents and events, their quantity and damage suffered allows us to evaluate the effectiveness of economic security management methods and related restrictions to form competitive strategies for the development of one of the most important competitive advantages - the security of the transportation process.

Evaluating the place of rail transport in the transportation market, one should systematically create competitive advantages in all areas of improving the quality of transport products and services, paying particular attention to the safety of the transportation process, as the most important priority in protecting the economic interests of all participants in the transportation process. 


\section{References}

1. L.V. Shkurina, S.N. Beriakov, The concept and methodology for the formation of the business potential of railway transport: the investment aspect (2016)

2. Shkurina, E.A. Maskaeva, A.A. Alferova, Economic management of rail competitiveness, 222 (2018)

3. N.P. Tereshina, V.A. Podsorin; Ed. N. P. Tereshina, Management of Innovations in Railway Transport, 592 (2012)

4. V.A. Podsorin, Transp., Sci., Tech. manag. Sci. Inf. Colle., 6 (2007)

5. N.P. Tereshina, Economic Regulation and Transportation Competitiveness, 131 (2015) 